\title{
Role of Complement in Mouse Macrophage Binding of Haemophilus influenzae type b
}

Gary J. Noel, David M. Mosser, and Paul J. Edelson

Department of Pediatrics, Division of Infectious Diseases and Immunology, and Department of Otorhinolaryngology, The New York Hospital-Cornell University Medical College, New York, New York 10021

\begin{abstract}
Previous in vivo studies demonstrated that clearance of encapsulated Haemophilus influenzae from blood is associated with the deposition of $\mathrm{C3}$ on these bacteria and is independent of the later complement components (C5-C9). Since clearance of encapsulated bacteria is determined by phagocytosis of bacteria by fixed tissue macrophages, we studied the interaction of $H$. influenzae type b with macrophages in vitro. Organisms bound to macrophages in the presence of nonimmune serum. Binding was not evident in heat-treated serum or in serum from complement depleted animals and was inhibited by $F\left(\mathbf{a b}^{\prime}\right) 2$ fragments of antibody to $\mathrm{C} 3$ and by blockade of the macrophage complement receptor type 3 . The majority of organisms bound in the presence of complement alone remained extracellular. Antibody in the form of convalescent serum or an IgG1 monoclonal to type b capsule did not increase the total number of organisms associated with macrophages, but did increase the number of organisms ingested. Furthermore, complement enhanced antibody-mediated ingestion. This in vitro study demonstrates that complement largely mediates binding of $\boldsymbol{H}$. influenzae to macrophages. This binding may be critical in determining the early clearance of these bacteria from blood and may be an important mechanism of defense in the nonimmune, as well as the immune host. (J. Clin. Invest. 1990. 85:208218.) complement $\cdot$ complement receptor type $3 \cdot \boldsymbol{H}$. influenzae type b - macrophages
\end{abstract}

\section{Introduction}

Phagocytosis is an important host defense mechanism against encapsulated Haemophilus influenzae type b (1-6). Ingestion of these organisms at local sites of infection by polymorphonuclear leukocytes (PMNs) may be important in preventing spread of infection, whereas phagocytosis by fixed macrophages effects the clearance of bacteria from blood (7). This macrophage-dependent clearance is critical in protecting the host from disseminated infection (8). Virulent $H$. influenzae type $b$, which can cause sustained, high-magnitude bacteremia, does so by evading or overwhelming antibody-independent mechanisms of host defense $(9-12)$. The mechanisms by

This work was presented in part at the 1988 Annual Meeting of the Society for Pediatric Research, Washington, DC.

Address reprint requests to Dr. Noel, N-834, The New York Hospital, 525 East 68th Street, New York, NY 10021.

Received for publication 1 September 1988 and in revised form 28 April 1989.

J. Clin. Invest.

(c) The American Society for Clinical Investigation, Inc. 0021-9738/90/01/0208/11 $\$ 2.00$

Volume 85, January 1990, 208-218 which this organism evades host defenses, however, are poorly understood. A recent in vivo study from our laboratory suggested that complement plays a major role as an opsonin in determining the antibody-independent clearance of $H$. influenzae from blood (6). Clearance was impaired relative to that seen in C3-depleted animals, but was not dependent upon the terminal components of complement. These results are consistent with observations of others that suggest complement is critical for the normal clearance of these bacteria from blood (13) and with the observations that patients with deficiencies in the early components of complement $(\mathrm{Cl}-\mathrm{C} 3)$ are at increased risk for $H$. influenzae infection while those deficient in the late components (C5-C9) are not $(14,15)$. Together these observations suggest that complement plays an important role as an opsonin in the host defense against $\boldsymbol{H}$. influenzae type $\mathrm{b}$, similar to its role with other bacteria including Streptococcus pneumoniae (16), Escherichia coli (17), and Legionella pneumophila (18).

The study presented here was conducted in order to better characterize mechanisms of host defense in an in vitro model system. We studied the opsonic effect of serum from nonimmune animals in which blood clearance of $H$. influenzae type b had been previously defined (6) and assessed the role of complement in effecting phagocytosis using the phagocyte responsible for blood clearance, the macrophage.

\section{Methods}

Sera. Nonimmune serum (NI-S) ${ }^{1}$ and serum from cobra venom factor treated mice (CoVF-S) was collected from male B10.D2/oSn mice (Jackson Laboratories, Bar Harbor, ME) and stored at $-70^{\circ} \mathrm{C}$ as described (6). Clearance of $H$. influenzae type b from blood has been defined in our laboratory in nonimmune and CoVF treated mice. In this study $(6), 54 \%(7 / 13)$ of nonimmune animals were no longer bacteremic and four of the six $(66 \%)$ bacteremic animals had $>100$ fold reduction in quantitative bacteremia by $24 \mathrm{~h}$ after intravenous inoculation of $H$. influenzae type b. In contrast, only $17 \%(2 / 12)$ of these C3-depleted animals were no longer bacteremic and none of the bacteremic animals had reduced their quantitative bacteremia 100 fold by $24 \mathrm{~h}$.

Serum complement activity was inactivated by heating serum at $56^{\circ} \mathrm{C}$ for $45 \mathrm{~min}$. Convalescent serum (Con-S) was collected from mice $4 \mathrm{wk}$ after the last of two biweekly inoculations of $H$. influenzae type b (Eagan isolate) and was stored at $-70^{\circ} \mathrm{C}$.

C3 levels in serum were assessed by radial immunodiffusion (RID) (6) and by a serum C3 fixation immunofluorescent assay (IFA) (6). C3 levels in NI-S and Con-S ranged from 290 to $359 \mathrm{mg} / \mathrm{dl}$ by RID. C3

1. Abbreviations used in this paper: Con-S, convalescent serum; CoVF-S, cobra venom factor serum; IFA, immunofluorescent assay; NI-S, nonimmune sera; PRP, polyribosylribitol phosphate; RID, radial immunodiffusion. 

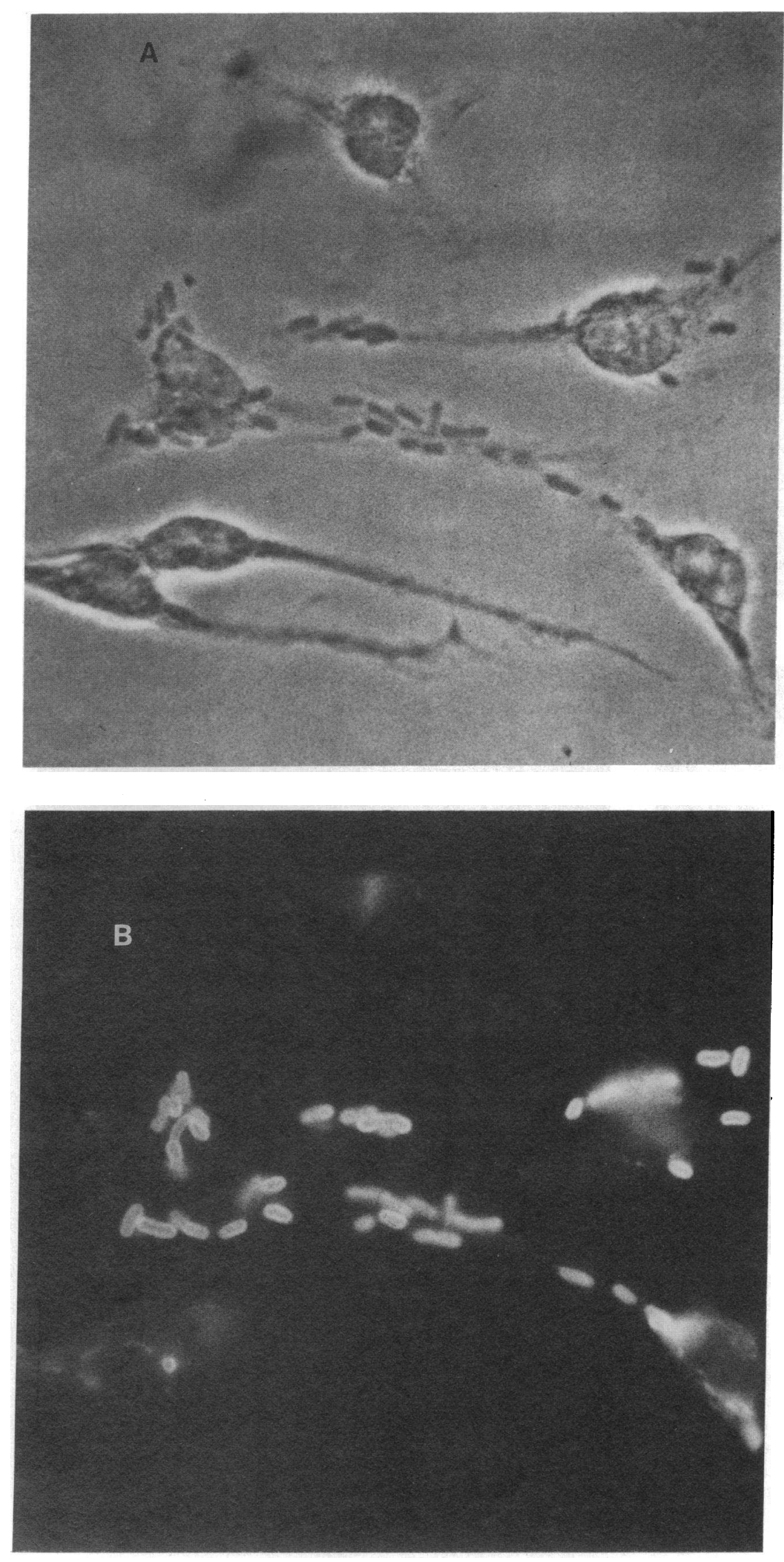

Figure 1. Resident peritoneal macrophages adherent to glass coverslips after $60 \mathrm{~min}$ incubation with $H$. influenzae type b (Eagan isolate) in the presence of $8 \%$ nonimmune mouse serum. Monolayer was fixed with methanol and incubated with rabbit antiserum to type $b$ organisms followed by incubation with FITC-conjugated goat antibody to rabbit immunoglobulin. $(A)$ Field as viewed with phase contrast microscopy. (B) Same field as viewed with fluorescent microscopy. 

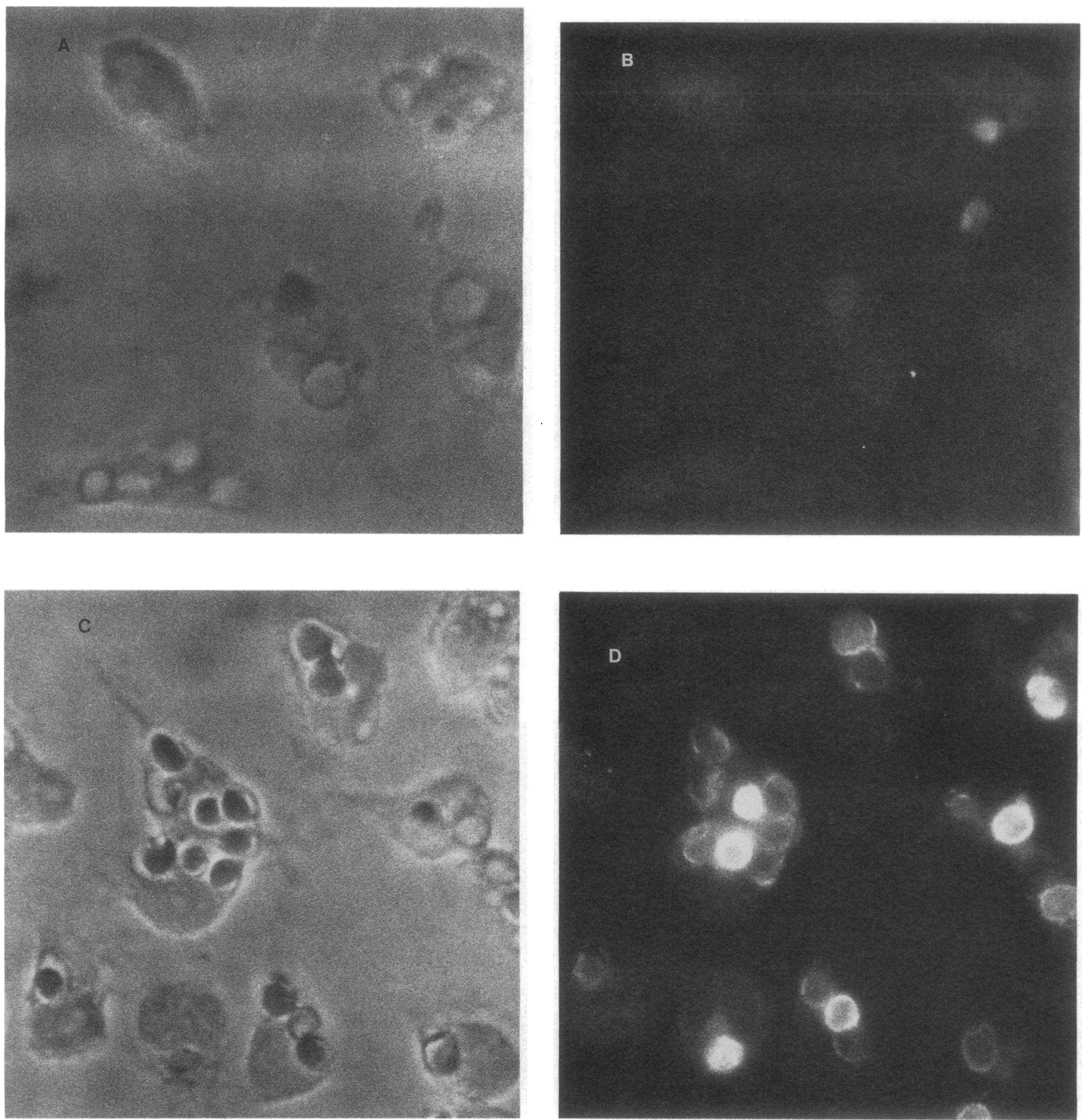

Figure 2. Resident mouse peritoneal macrophages with either ingested IgG-coated sheep erythrocytes $(A-F)$ or IgGl opsonized $H$. influenzae type $\mathrm{b}(G-J)$. Monolayers were fixed in $3.3 \%$ neutral buffered formalin $(A, B, G, H), 100 \%$ methanol $(C, D, J, I)$, or $3 \%$ paraformaldehyde $(E$ and $F$ ), and then incubated in either rabbit antibody to sheep erythrocytes $(A-F)$ or rabbit antiserum to $H$. influenzae type b $(G-J)$. Monolayers were then incubated with FITC-conjugated goat antibody to rabbit immunoglobulin. Fields are shown as viewed with phase contrast microscopy $(A, C, E, G, I)$, or with fluorescent microscopy $(B, D, F, H, J)$. Ingested erythrocytes were visualized with fluorescent microscopy in methanol-fixed monolayers $(D)$ as intensely fluorescent stained cells. This staining of ingested erythrocytes was not seen after formalin $(B)$ or paraformaldehyde $(F)$ fixation. Similarly, staining of $H$. influenzae after formalin fixation $(H)$ was much less than that seen after methanol fixation $(J)$, suggesting the majority of bacteria were intracellular rather than peripherally bound following incubation in the presence of type specific monoclonal mouse IgG1 antibody. Arrows indicate examples of stained bacteria and corresponding location on monolayers seen by phase contrast microscopy (methanol fixed, $I$ and $J$ ) and of apparent intracellular organisms as seen by phase microscopy and corresponding location of unstained bacteria (formalin fixed, $G$ and $H$ ). 

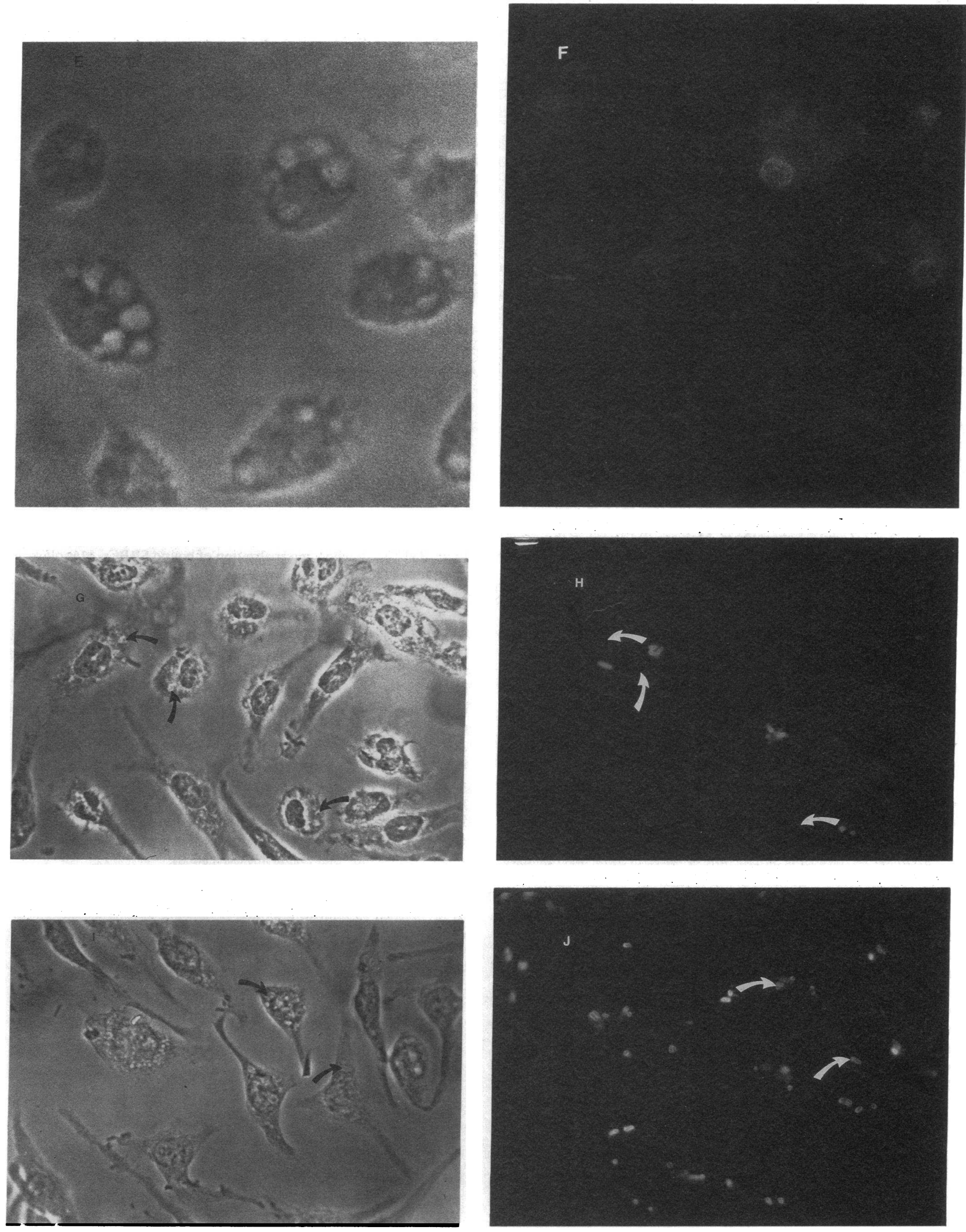

Figure 2 (Continued) 
fixation titers by IFA ranged from 1:16 to 1:32. CoVF-S had C3 levels of less than $20 \mathrm{mg} / \mathrm{dl}$ by RID. C3 fixation was not detected by IFA in CoVF-S or in heat-inactivated serum.

Serum IgG and IgM antibody was measured by an ELISA to whole organisms (6). Pooled NI-S had a titer $<1: 10$, the lower limits of detection of antibody with this assay. Con-S had a titer of 1:2,560. Monoclonal antibody to type b capsule (E 117-5) assayed at a concentration of $100 \mu \mathrm{g} / \mathrm{ml}$ had an ELISA titer of 1:320.

Organisms. Four isolates of $\boldsymbol{H}$. influenzae type $\mathrm{b}$, were suspended in skim milk broth (Difco Laboratories, Detroit, MI) and stored at $-70^{\circ} \mathrm{C}$. Isolate Eag (Eagan strain) has been previously studied $(2,3,6)$ and was derived from a clinical blood isolate. Isolate R-56 (strain $\mathrm{KW} 20 \mathrm{~b}$ ), a type b transformant of a capsule-deficient isolate (19), was provided by Dr. T. Stull (Medical College of Pennsylvania). Strain Asa was isolated from blood of a child with septic arthritis. Strain Nie was isolated from CSF.

Organisms were radiolabeled with methyl $-\left[{ }^{3} \mathrm{H}\right]$ thymidine $(20 \mathrm{Ci} /$ mmol sp act, New England Nuclear, Boston, MA) by $4 \mathrm{~h}$ incubation at $37^{\circ} \mathrm{C}$ in thymidine-poor Mueller Hinton Broth (Difco Laboratories) supplemented with NAD and hemin (20), containing $0.01 \mathrm{mCi} / \mathrm{ml}$ of $\left[{ }^{3} \mathrm{H}\right]$ thymidine. Organisms were washed twice and suspended in HBSS (Gibco Laboratories, Grand Island, NY) containing $0.2 \%$ glucose and $0.02 \%$ gelatin (PB). Label associated with organisms was calculated by dividing colony forming units/inoculum by counts per minute/inoculum. Label uptake ranged between 300 and $800 \mathrm{cfu} / \mathrm{cpm}$.

Complement deposition on bacteria. $\mathrm{C} 3$ fixation to bacteria in the presence of Con-S and NI-S was assessed by an IFA using an antibody to mouse $\mathrm{C} 3$ as previously described (6). The FITC-conjugated goat anti-mouse C3 (Cappel Laboratories, Malvern, PA) used in this assay recognized the $\mathrm{C} 3 \mathrm{c}$ portion of $\mathrm{C} 3$ and did not allow distinction of mouse C3b from C3bi. However, deposition of human $\mathrm{C} 3 \mathrm{~b}$ and/or $\mathrm{C} 3 \mathrm{bi}$ was assessed using reagents specific to human $\mathrm{C} 3 \mathrm{c}$ and $\mathrm{C} 3 \mathrm{bi}$ (clone 4 and clone 9, provided by P. Lachman, M. R. C., Cambridge, UK). Bacteria incubated for $30 \mathrm{~min}$ in 50\% human C8-deficient serum or $50 \%$ human agammaglobulinemic serum $(<70 \mathrm{mg} / \mathrm{dl} \mathrm{lgG})$ were incubated for $20 \mathrm{~min}$ in either clone 4 or 9 and then immunofluorescently stained (21). Antibodies to human C3c (clone 4) and C3bi (clone 9) did not react with mouse $C 3$ and could not be used to assess deposition of mouse $\mathrm{C} 3$ on bacteria.

Macrophages. Resident peritoneal macrophages were obtained from CDF-1 mice (Charles River Breeding Laboratories, Wilmington, MA) as described by us (21). The number of macrophages per well (between $8 \times 10$ [4] and $3.0 \times 10$ [5]) was assessed by counting adherent cells in each of five high power fields with an inverted microscope and extrapolating to total well bottom surface area (21).

Methods for assessing interaction of bacteria with macrophages. Association of organisms with macrophages was assessed by a radiobinding assay and by direct visualization using immunofluorescent microscopy of methanol fixed monolayers. Each assay measured both peripherally bound and internalized bacteria. Data from these assays are therefore expressed as "macrophage-associated organisms." The radiobinding assay was performed by addition of 1 to $5 \times 10$ (7) tritium-labeled organisms to monolayers of 0.8 to $3.0 \times 10$ (5) macrophages adherent to the bottom of plastic wells in a total volume of 0.30 $\mathrm{ml}$. Bacteria were incubated in the presence or absence of sera with macrophage monolayers for $1 \mathrm{~h}$ at $37^{\circ} \mathrm{C}$. Monolayers were then washed three times with warm PB to remove unbound organisms and lysed with $400 \mu$ of $0.5 \%$ Triton X-100 (Mallinckrodt, Inc., Paris, KY). Lysate was aspirated from wells, added to $3.5 \mathrm{ml}$ of Aquassure (New England Nuclear) and counted. The number of organisms associated with macrophages were determined by dividing the calculated macrophage-associated organisms per well (cpm/lysate $\times \mathrm{cfu} / \mathrm{cpm})$ by the number of macrophages/well. Experiments were done in duplicate or triplicate each day and results from each day's experiment were averaged. Background binding to plastic well bottoms was assessed by measuring counts per minute associated with wells not containing monolayers. Mean background binding counts for all experiments was $61 \pm 17 \mathrm{cpm} /$ well and never exceeded $84 \mathrm{cpm} /$ well. Nonspecific bind- ing to mouse fibroblasts (NCTC clone 929, American Type Culture Collection) was assessed by measuring counts per minute associated with monolayers incubated under identical conditions.

Direct visualization of monolayers by immunofluorescence confirmed radiobinding data. After incubation with bacteria, washed monolayers were fixed for $2 \mathrm{~min}$ in $100 \%$ methanol, washed, and then exposed for $20 \mathrm{~min}$ to a 1:100 dilution of rabbit antiserum to $H$. influenzae type $b$ (Difco). Cells were then washed three times in PB and incubated for $20 \mathrm{~min}$ in a 1:100 dilution of FITC-conjugated goat antibody to rabbit immunoglobulin (Meloy Laboratories, Springfield, VA). After a final wash monolayers were examined with a Zeiss fluorescent microscope (Carl Zeiss, Thornwood, NY). Using this technique both intracellular and extracellular organisms were visualized (Fig. 1). The number of organisms associated with macrophages was determined by counting the number of bacteria associated with 100 macrophages.

Ingestion of organisms was distinguished from binding by comparing the number of immunofluorescent-stained organisms associated with methanol-fixed macrophages to the number seen associated with formalin-fixed macrophages. Similar to previous observations (22), $100 \%$ methanol fixation permitted immunofluorescent staining of all cell-associated particles while formalin or paraformaldehyde fixation permitted staining of only those particles peripherally bound. As a control, the exclusion of fluorescent antibody staining of internalized particles in formalin-fixed monolayers was demonstrated with ingested sheep red blood cells (SRBCs). SRBCs preincubated for $30 \mathrm{~min}$ at $37^{\circ} \mathrm{C}$ in a $1: 5,000$ dilution of rabbit antibody to SRBC (Cordis Laboratories, Miami, FL) were incubated with monolayers for $1 \mathrm{~h}$. Monolayers were then washed to remove unbound SRBCs and incubated an additional hour to allow internalization of bound SRBCs. Monolayers were then washed and fixed in either 3.3\% formalin (formalin solution, neutral buffered; Sigma Chemical Co., St. Louis, MO, final preparation contained less than $5 \%$ methanol), $100 \%$ methanol, or $3 \%$ paraformaldehyde. Fixed monolayers were then incubated for two 20-min periods in a 1:100 dilution of rabbit antibody to SRBCs (Cordis Laboratories) and a 1:100 dilution of FITC-conjugated goat antibody to rabbit immunoglobulin. Ingested SRBCs were identified by a rim of intense fluorescence in methanol-fixed monolayers but were not evident in formalin- or paraformaldehyde-fixed macrophages (Fig. 2, $A-F$ ). These same fixation and similar immunofluorescent staining techniques were used to assess ingestion versus binding of $H$. influen$z a e$ (Fig. 2, G-J). The number of organisms ingested was calculated by subtracting the number of bound bacteria (formalin fixed) from the number of macrophage associated organisms (methanol fixed). For each experiment an ingestion index was calculated as: 1 - (number of organisms bound/total organisms associated).

In sequential incubation assays monolayers adherent to glass coverslips were incubated with organisms and $8 \%$ serum (NI-S) for $1 \mathrm{~h}$ at $37^{\circ} \mathrm{C}$, washed to remove unbound organisms, and reincubated with either buffer containing antibody, $8 \%$ heat inactivated Con-S, $8 \%$ heat inactivated NI-S, or $8 \%$ fresh NI-S for $30 \mathrm{~min}$. Monolayers were then prepared and fixed as above.

Antibodies and macrophage receptor blockade. Monoclonal antibody $\mathrm{M} 1 / 70$, a rat IgG2b antibody to the alpha chain of MAC 1 , the mouse macrophage complement receptor CR3, was prepared as described (21). Inhibition of CR3-dependent binding was achieved by adding $8 \mu \mathrm{g}$ of monoclonal antibody after the final PB wash of monolayers $20 \mathrm{~min}$ before adding particles as described (21). Similar results obtained with purified antibody were achieved using $3 \%$ culture supernatant. These concentrations of antibody were chosen to give maximal inhibition of $H$. influenzae binding in the presence of $8 \%$ fresh mouse serum but less than $10 \%$ inhibition of IgG-coated SRBC binding in the absence of serum.

Inhibition of binding to the lectin-like site of the CR3 was achieved using $N$-acetyl-D-glucosamine (NADG; Sigma) (23). Monolayers preincubated in $100 \mathrm{mM}$ NADG for 20 min resulted in a $50 \%$ inhibition of serum independent zymosan binding and had no effect on IgG-coated SRBC binding. 
Monoclonal antibody M18/2.a.8 was prepared using methods identical to those used to prepare M1/70. This rat IgG2a antibody recognizes the beta chain of leukocyte antigens p150,95, CR3, and LFA-1. Consistent with previous observations (24) there was no effect on binding of either IgG- or IgM complement-coated SRBCs when this reagent was used at concentrations of $70 \mu \mathrm{g} / \mathrm{ml}$ protein of culture supernatant. This concentration resulted in maximal fluorescence following immunofluorescent staining of monolayers.

Monoclonal antibody 2.4G2, provided by Dr. E. Pure (The Rockefeller University, New York), is a rat IgG2 antibody that recognizes mouse Fc receptor 2 and inhibits binding of IgG1-, IgG2b-, and IgG2a-coated particles to murine mononuclear phagocytes (25). Monolayers preincubated with this antibody for $20 \mathrm{~min}$ at a concentration of $10 \mu \mathrm{g} /$ well resulted in $90 \%$ inhibition of IgG-coated SRBCs and had no effect on binding of C3-coated SRBCs.

$\mathrm{F}\left(\mathrm{ab} \mathrm{b}^{\prime}\right) 2$ fragments of goat antibody to mouse $\mathrm{C} 3$ (Cappel, Organon Teknika Corp., West Chester, PA) were used to inhibit C3-mediated binding. This reagent used at a concentration of $500 \mu \mathrm{g} / \mathrm{ml}$ inhibited $85 \%$ of C3-coated red blood cell binding but $<10 \%$ of IgG-coated SRBC binding to macrophages.

A mouse IgG1 purified monoclonal antibody (E 117-5) directed against polyribosyl ribitol phosphate (PRP) was provided by Praxis Laboratories (Rochester, NY). This antibody was diluted in PB and used at a final concentration of $6.7 \mu \mathrm{g} / \mathrm{ml}$.

Polyclonal rabbit antiserum to the protein encoded by murine gene CRY (mCRY), a gene shown to be homologous to the gene encoding for human CR1 (26), was provided by Dr. J. H. Weis (University of Utah). Monoclonal antibodies including $8 \mathrm{C12}$, a rat IgG antibody to a $190,000 M_{\mathrm{r}}$ mouse leukocyte surface protein shown to mediate binding of C3b-coated particles (27), were provided by Dr. T. Kinoshita (Osaka, Japan). Polyclonal rabbit serum to the protein encoded for by mCRY used at $35 \mu \mathrm{g} / \mathrm{ml}$ protein and purified monoclonal antibodies used at a concentrations of $10-30 \mu \mathrm{g} / \mathrm{ml} \mathrm{did} \mathrm{not} \mathrm{inhibit} \mathrm{the} \mathrm{binding} \mathrm{of}$ C3-coated SRBCs or C3-coated $H$. influenzae type b to resident macrophages. Monolayers incubated with these reagents at these concentrations failed to show fluorescence while monolayers incubated with $\mathrm{M} 1 / 70(2.6 \mu \mathrm{g} / \mathrm{ml})$ demonstrated macrophage membrane fluorescence. These observations suggest that receptor for $\mathrm{C} 3 \mathrm{~b}$ expression in unstimulated mouse phagocytes may be considerably less than expression of CR3 in these cells (27).

Effect of reagents on binding and ingestion of organisms was calculated for each experiment as an inhibition index: 1 - (number of organisms associated in presence of reagent/number of organisms associated without reagent).

Statistical analysis. Differences were compared using Student's $t$ test (28). Differences between indices (nonparametric data) were compared using Wilcoxon's rank sum test (28). Estimates of variance were calculated as the standard deviation (28).

\section{Results}

Complement deposition on $\mathrm{H}$. influenzae. $\mathrm{C} 3$ deposition on all four isolates of $H$. influenzae type b after a 30-min incubation in nonimmune and convalescent mouse serum was demonstrated by immunofluorescent staining of organisms with FITC-conjugated anti-mouse C3 (6). C3 deposition was not evident after incubation without serum, with serum from cobra venom factor-treated animals, with serum heated to $56^{\circ} \mathrm{C}$ for $45 \mathrm{~min}$ or with purified monoclonal antibody E1 17-5 in the absence of fresh mouse serum.

C3bi deposition on $H$. influenzae type b after incubation with human serum was also assessed by immunofluorescence using clone 9 monoclonal antibody to human C3bi. C3bi was deposited on all four isolates of $H$. influenzae after a $30-\mathrm{min}$ incubation in either $\mathrm{C} 8$ deficient or agammaglobulinemic human serum.
Effect of nonimmune serum on $H$. influenzae type $b$ interaction with macrophages. Radiobinding assays and direct visualization of fluorescent stained monolayers were used to measure the number of organisms associated with macrophages. The average number of organisms associated with macrophages in the absence of serum as determined by the radiobinding assay was $0.2 \pm 0.3$ organisms/macrophage. Direct visualization of these monolayers consistently showed $<0.1$ organisms/macrophage even in experiments where the inoculum exceeded 800 organisms/macrophage.

Nonimmune serum enhanced the interaction of all four isolates of $H$. influenzae type b studied with macrophage monolayers (Table I). The number of organisms associated with monolayers as determined by the radiobinding assay ranged from 3 to 18 organisms per macrophage corresponding to between 800 and $3,500 \mathrm{cpm} /$ well above background and increased with the size of the inoculum (Fig. 3). These radiobinding results were confirmed by direct visualization of methanol-fixed, fluorescent-stained monolayers. The number of organisms observed to be associated with macrophages was similar to the number calculated using the radiobinding assay.

Association of organisms with macrophage monolayers was not evident when heat-inactivated serum or serum from CoVF-treated mice was used (Table I). The number of organisms associated with monolayers in the presence of these sera was not significantly different from the number associated with monolayers in the absence of serum. Lack of association of organisms with macrophages in the presence of these sera was confirmed by the radiobinding assay.

As another measure of the specificity of this interaction the interaction of organisms with fibroblasts was studied. Using radiolabeled organisms the calculated number of organisms associated with fibroblasts was $<0.5$ organisms/macrophage corresponding to $<100 \mathrm{cpm} /$ well.

Table I. Association of Four Isolates of $H$. influenzae type $b$ with Resident Mouse Peritoneal Macrophages in the Absence of Serum or in the Presence of Nonimmune Serum (NI-S), Heatinactivated Serum (HI-S), or Serum from Complement-depleted, Cobra Venom Factor-treated B10. D2/oSn Mice (CoVF-S)

\begin{tabular}{lcccc}
\hline & \multicolumn{4}{c}{ Number of organisms/macrophage } \\
\cline { 2 - 5 } \multicolumn{1}{c}{ Isolate } & No serum & NI-S & HI-S & CoVF-S \\
\cline { 2 - 5 } $\begin{array}{c}\text { mean inoculum size } \\
\pm S D\end{array}$ & & & & \\
EAG & $0.0 \pm 0.0^{*}$ & $10.8 \pm 2.2$ & $0.0 \pm 0.0$ & $0.1 \pm 0.2$ \\
$(540 \pm 61)$ & $(0.1 \pm 0.3)^{\ddagger}$ & $(6.8 \pm 3.6)$ & $(0.1 \pm 0.1)$ & $(0.1 \pm 0.2)$ \\
R-56 & $0.0 \pm 0.0$ & $8.7 \pm 1.6$ & $0.0 \pm 0.0$ & $0.0 \pm 0.0$ \\
$(588 \pm 77)$ & $(0.5 \pm 0.6)$ & $(14.0 \pm 5.0)$ & $(0.0 \pm 0.0)$ & $(0.0 \pm 0.0)$ \\
NIE & $0.0 \pm 0.0$ & $13.4 \pm 2.5$ & $0.0 \pm 0.0$ & $0.2 \pm 0.2$ \\
$(494 \pm 137)$ & $(0.4 \pm 0.6)$ & $(8.0 \pm 5.4)$ & $(0.1 \pm 0.1)$ & $(0.2 \pm 0.2)$ \\
ASA & $0.0 \pm 0.0$ & $17.7 \pm 1.7$ & $0.0 \pm 0.0$ & $0.0 \pm 0.1$ \\
$(482 \pm 129)$ & $(0.3 \pm 0.6)$ & $(11.3 \pm 5.3)$ & $(0.2 \pm 0.2)$ & $(0.0 \pm 0.1)$ \\
& & & &
\end{tabular}

* Number of organisms/macrophage \pm SD for four experiments as determined by direct examination of methanol fixed monolayers after immunofluorescent staining of type $b$ organisms.

₹ Number of organisms/macrophage \pm SD for two experiments determined by calculation of radiolabeled organisms associated with monolayers. Inoculum sizes ranged from 200 to 400 organisms/macrophage. 


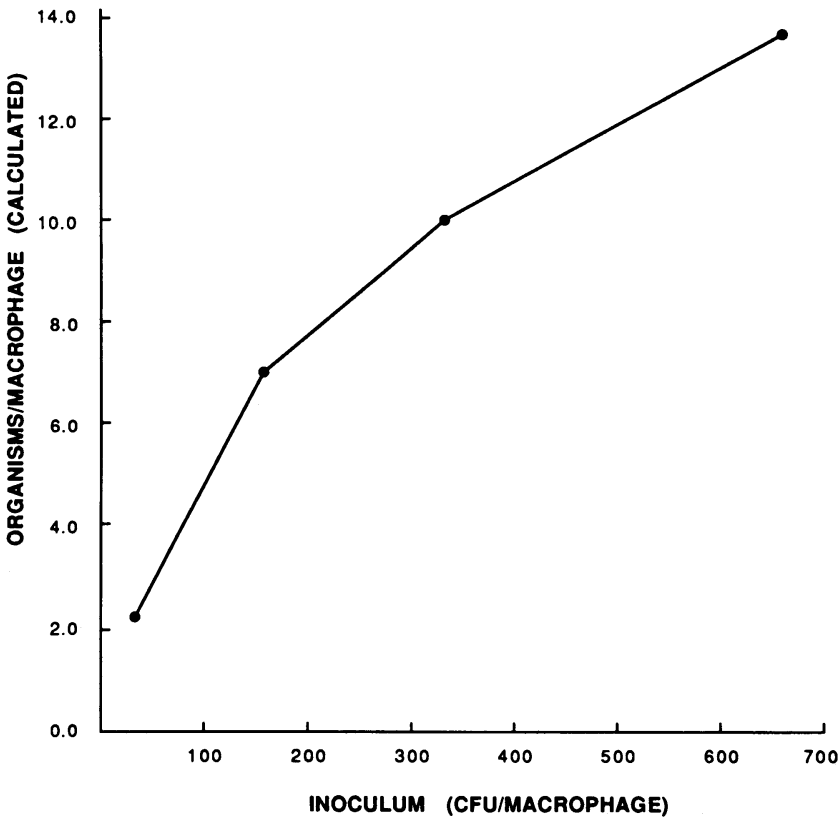

Figure 3. Effect of inoculum size on number of organisms (Eagan isolate) associated with mouse resident peritoneal macrophage monolayers in the presence of $8 \%$ nonimmune mouse serum. The number of organisms associated with macrophages was determined by measuring the amount of radioactivity associated with monolayers after $60 \mathrm{~min}$ incubation of tritium-labeled organisms with monolayers adherent to the bottom of plastic wells. Points indicate the mean number of calculated organisms/macrophage of duplicate wells for a single day's experiment where inoculum varied from $\mathbf{3 0}$ $\mathrm{cfu} /$ macrophage to $656 \mathrm{cfu} / \mathrm{macrophage}$.

Effect of $F\left(a b^{\prime}\right) 2$ anti-C3 fragments on serum-dependent binding and ingestion. $\mathrm{F}\left(\mathrm{ab}^{\prime}\right) 2$ fragments to murine $\mathrm{C} 3$ were used to specifically inhibit C3-dependent opsonization and binding to macrophages. This reagent used at a concentration of $500 \mu \mathrm{g} / \mathrm{ml}$ inhibited $85 \%$ of rabbit red blood cell binding to macrophages in the presence of C5 deficient serum but $<10 \%$ of IgG coated sheep red blood cell binding. $F\left(a^{\prime}\right) 2$ fragments $(500 \mu \mathrm{g} / \mathrm{ml})$ were added to monolayers before and during in- cubation with $H$. influenzae type b (Eagan strain) in the presence of serum. Under these conditions the number of organisms associated with macrophages as determined by direct visualization was reduced from the control value of 10.7 organisms/macrophage to $0.2 \mathrm{organism} / \mathrm{macrophage} \mathrm{(inhibi-}$ tion index $0.99 \pm 0.01$ ), the level seen when macrophages were incubated with organisms in the absence of serum (Table II). Antibody fragments to $\mathrm{C} 3$ had little inhibitory effect when the organisms were incubated with monoclonal antibody to $H$. influenzae type b (Table II). Interestingly, this anti-C3 reagent also reduced bacterial association to levels approximating background when monolayers were incubated in the presence of convalescent serum (Table II).

Effect of antiserum to CR3 on serum dependent binding and ingestion. $\mathrm{CR} 3$ receptor blockade was achieved by incubation of monolayers with monoclonal antibody M1/70. This reagent did not affect IgG sheep red cell binding but did inhibit C3bi red cell rosetting by $90 \%$. As measured by direct visualization this monoclonal antibody inhibited the association of all four isolates with macrophages in the presence of nonimmune serum (Fig. 4). This inhibition was significantly greater $(P<0.05$ by rank sum test) than that seen following incubation with comparable concentrations of monoclonal antibody 2.4G2 and antibody M18/2.a.8. Radiobinding assays confirmed this inhibition and demonstrated at least a $75 \%$ inhibition at all inoculum sizes studied (range 200-820 organisms/ macrophage) for all four isolates. Similar to $F\left(a b^{\prime}\right) 2$ anti-C3 inhibition results, CR3 blockade inhibited the association of organisms in the presence of convalescent serum (Table II). Interestingly, this reagent inhibited $\sim 50 \%$ of the macrophage-associated organisms in the presence of IgG1 monoclonal against PRP (Table II). This observation is similar to those made using anti-human CR3 monoclonal antibodies, human neutrophils and IgG coated particles (24).

Inhibition of the association of particles via the lectin-like site of CR3 was assessed using NADG. $100 \mathrm{mM}$ NADG reduced zymosan binding from $1.3 \pm 0.4$ to $0.7 \pm 0.1$ particles/ macrophage $(n=3)$ similar to that described with neutrophils (24). However, NADG had no effect on $\boldsymbol{H}$. influenzae type b binding to macrophages in the presence of $8 \%$ nonimmune serum $(10.7 \pm 2.1$ vs. $11.5 \pm 1.7$ organisms/macrophage, $n=4$, mean inoculum $\pm \mathrm{SD}=455 \pm 114 \mathrm{CFU} /$ macrophage) .

Table II. Effect of Incubation with F(ab')2 Anti-mouse C3, with Monoclonal Antibody M1/70 (Anti-CR3) or with Monoclonal Antibody 2.4G2 (Anti-Fc Receptor) on the Association of H. influenzae type b (Eagan Isolate) with Mouse Resident Peritoneal Macrophages in the Presence of Nonimmune (Ni-S), Convalescent (Con-S), or IgG1 Mouse Monoclonal Antibody to PRP

\begin{tabular}{|c|c|c|c|c|c|c|c|}
\hline \multirow[b]{3}{*}{ Opsonin } & \multicolumn{7}{|c|}{ Organisms/macrophage* } \\
\hline & \multirow{2}{*}{$\begin{array}{c}\text { Control }^{\ddagger} \\
\text { Total associated }\end{array}$} & \multicolumn{2}{|c|}{$F\left(a b^{\prime}\right) 2$ anti-C3 } & \multicolumn{2}{|c|}{ M1/70 } & \multicolumn{2}{|c|}{$2.4 \mathrm{G} 2$} \\
\hline & & Total associated & Inhib. index ${ }^{8}$ & Total associated & Inhib. index & Total associated & Inhib. index \\
\hline $\mathrm{Ni}-\mathrm{S}$ & $10.7 \pm 2.7$ & $0.2 \pm 0.4^{\prime \prime}$ & $0.99 \pm 0.00$ & $0.3 \pm 0.3^{\| \prime}$ & $0.96 \pm 0.00$ & $9.5 \pm 0.8^{\prime \prime}$ & $0.15 \pm 0.26$ \\
\hline Con-S & $11.2 \pm 3.6$ & $0.0 \pm 0.0^{\prime \prime}$ & $1.0 \pm 0.0$ & $0.8 \pm 0.9^{\prime \prime}$ & $0.95 \pm 0.04$ & $10.0 \pm 2.9^{\pi}$ & $0.16 \pm 0.15$ \\
\hline IgG1 & $10.5 \pm 1.7$ & $8.6 \pm 2.9^{\prime \prime}$ & $0.24 \pm 0.21$ & $5.3 \pm 1.4^{\| \prime}$ & $0.50 \pm 0.19$ & $0.0 \pm 0.0^{\prime \prime}$ & $1.0 \pm 0.0$ \\
\hline
\end{tabular}

* Mean number of $H$. influenzae type b (Eagan isolate) per macrophage \pm standard deviation as determined by immunofluorescent microscopy. Mean inoculum size $( \pm \mathrm{SD})$ for control, $\mathrm{F}\left(\mathrm{ab}^{\prime}\right) 2$ and M1/70 experiments $(n=6)$ was $570 \pm 66$ and for $2.4 \mathrm{G} 2$ experiments $(n=3)$ was $555 \pm 78$. ${ }^{\ddagger}$ Mean number of organisms associated with macrophages in Ni-S alone. ${ }^{\S}$ Mean inhibition index \pm SD as determined by calculation of this index for each experiment as: 1 - (organisms associated in presence of reagent/organisms associated without reagent). Indices significantly different as determined by rank sum, $P<0.05$, for $\mathrm{F}\left(\mathrm{ab}^{\prime}\right) 2$ and $\mathrm{M} 1 / 70$ experiments compared to $2.4 \mathrm{G} 2$ experiments for each opsonin. " Difference significant, $P<0.01$, when compared to control values. 'Difference not significant, $P>0.1$, when compared to control values. 


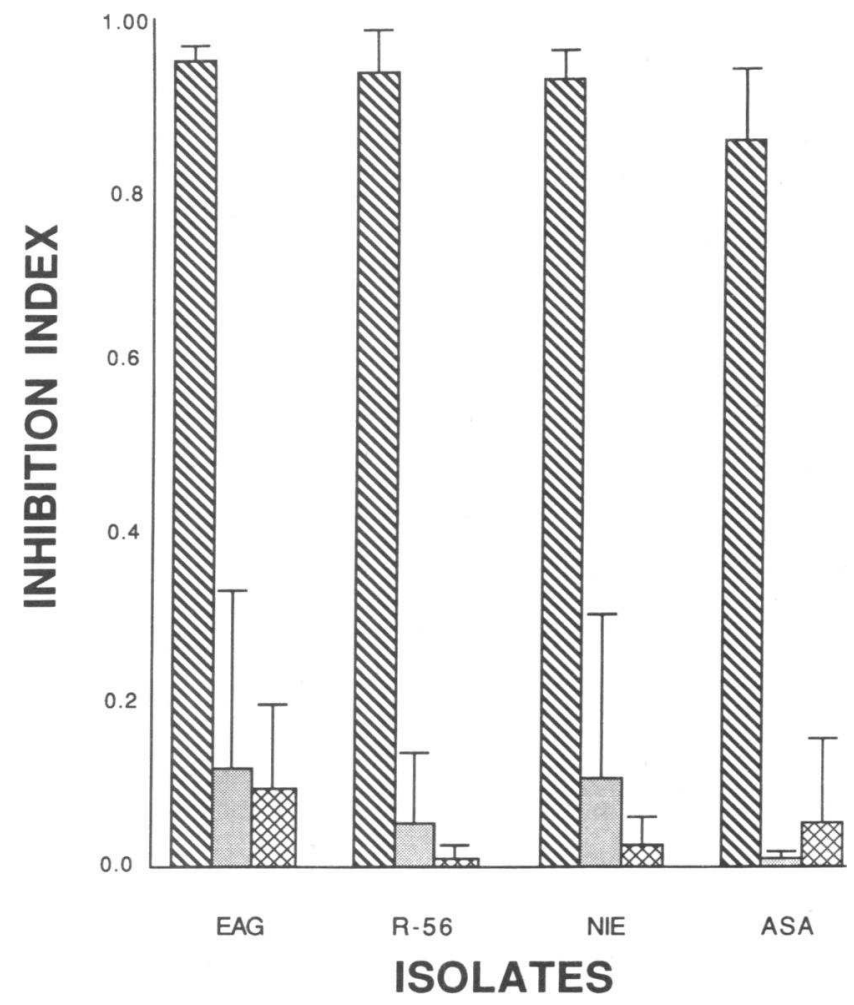

Figure 4. Effect of monoclonal antibodies M1/70, 2.4G2, and M18/2.a.8 on the total number of $H$. influenzae type b associated with resident peritoneal macrophages incubated in the presence of $8 \%$ nonimmune mouse serum. Organisms associated with monolayers were determined by direct visualization of four isolates of $H$. influenzae type b (EAG, R-56, NIE, ASA) following immunofluorescent staining. Inhibition index was calculated for each experiment as: 1 - (organisms associated in presence of monoclonal/organisms associated in the absence of monoclonals). Results of four experiments. Striped bars represent inhibition index $( \pm S D)$ after incubation in the presence of $2.7 \mu \mathrm{g} / \mathrm{ml} \mathrm{M} 1 / 70$. Dotted bars represent inhibition index $( \pm \mathrm{SD})$ after incubation in presence of $3.3 \mu \mathrm{g} / \mathrm{ml} 2.4 \mathrm{G} 2$ and hatched bars represent the inhibition index $( \pm \mathrm{SD})$ in the presence of concentrated culture supernatant $(70 \mu \mathrm{g} / \mathrm{ml}$ protein) of M18/2.a.8. Inhibition indices of $\mathrm{M} 1 / 70$ for each isolate differ significantly as determined by rank sum, $P<0.05$, compared to indices of $2.4 \mathrm{G} 2$ and M18/2.a.8.

Monoclonal antibody to Fc receptor, 2.4G2, was used in parallel to these experiments. The concentration of antibody chosen $(10 \mu \mathrm{g} /$ well $)$ reduced $\mathrm{IgG}$ mediated sheep red cell binding by $90 \%$. Antibody $2.4 \mathrm{G} 2$ completely inhibited binding and ingestion of $H$. influenzae type $\mathrm{b}$ in the presence of $\mathrm{IgG} 1$ monoclonal antibody E 117-5 (Table II) but had little or no effect on organism association with macrophages in the presence of nonimmune serum (Fig. 4). This reagent did not significantly affect the total number of organisms associated with monolayers in the presence of convalescent serum (Table II). Incubation with $2.4 \mathrm{G} 2$, however, did reduce the mean ingestion index under these conditions from 0.47 to $0.20(P<0.05$ by rank sum) $(12.3 \pm 4.0$ total associated/6.4 \pm 3.4 total bound versus $11.0 \pm 2.7$ total associated/9.6 \pm 5.5 total bound, $n=4$, inoculum size $543 \pm 62$ ).

Effect of serum on binding versus ingestion of $H$. influenzae by macrophages. Differentiation of binding from ingestion of organisms by macrophages was accomplished by direct visual- ization and comparison of methanol-fixed to formalin-fixed monolayers. Using this method $89 \%$ of organisms that were visibly associated with macrophages in the presence of nonimmune serum were peripherally bound and not ingested (Table III). In contrast, incubation with convalescent serum, although not increasing the total number of organisms associated with macrophages, did increase the fraction of organisms ingested. As shown in Table III the percentage of organisms ingested rose from $11 \%$ to $55 \%$. Most ingested organisms appeared to be within cytoplasmic vacuoles as seen with phase contrast microscopy. These ingested organisms were not visible when examined by fluorescent microscopy after formalin fixation but were clearly fluorescent in methanol fixed monolayers (Fig. 2, $G-J$ ).

Similar results were obtained with bacteria incubated in the presence of monoclonal antibody (E117-5) to $H$. influen$z a e$ type b. Incubation of monolayers with $H$. influenzae in the presence of $6.7 \mu \mathrm{g} / \mathrm{ml}$ of E1 17-5 resulted in a number of organisms associated with macrophages that was comparable to that achieved in $8 \%$ nonimmune serum. However, $87 \%$ of these organisms were ingested compared to the $11 \%$ that were ingested in the presence of nonimmune serum (Table II).

Sequential incubation experiments were performed using a reduced concentration $(2.3 \mu \mathrm{g} / \mathrm{ml})$ of purified monoclonal antibody and heat-inactivated convalescent serum. Each of these reagents was incapable of promoting binding and ingestion on its own. In experiments where monolayers were incubated with organisms and $8 \%$ nonimmune serum, washed, and then incubated with the reduced concentration of monoclonal antibody to $H$. influenzae type $\mathrm{b}$ the average number of organisms associated with macrophages was $21.4 \pm 0.3(n=2)$. The average number of organisms ingested after this sequential incubation was $10.5 \pm 0.3(n=2)$ and the mean ingestion index was $0.53 \pm 0.06$. Similarly, sequential incubations with $8 \%$ nonimmune serum and heat-inactivated convalescent serum resulted in $17.1 \pm 4.4$ organisms associated per macrophage with $8.6 \pm 3.5$ organisms ingested (mean ingestion index $0.48 \pm 0.12, n=4$ ). By comparison, monolayers incubated with organisms and $8 \%$ nonimmune serum, washed and again incubated with either $8 \%$ fresh nonimmune serum or with heat inactivated nonimmune serum resulted in $16.0 \pm 1.5$ organisms/macrophage $(n=2)$ and $11.8 \pm 3.3$ organisms/macrophage $(n=4)$, respectively, and the mean ingestion index for both of these sequential incubations was $<0.17$.

\section{Discussion}

Several previous in vivo studies have demonstrated that complement is involved in host defense against $H$. influenzae (6, $13,15)$. The results of the present study suggest a mechanism by which complement plays this role. In examining the interaction of $H$. influenzae with mouse peritoneal macrophages in vitro we found that these organisms do not bind to macrophages in the absence of serum. However, serum taken from animals which we have previously shown (6) to be capable of promptly clearing organisms from their blood stream, was able to efficiently promote the interaction of these organisms with macrophages. Further, the same procedures which impaired the clearance process in the animal also impaired the ability of serum from these animals to mediate this in vitro attachment. Both the in vivo process previously studied, and the in vitro phenomena reported in this paper, require the participation of 
Table III. Effect of Nonimmune Serum (NI-S), Convalescent Serum (Con-S), or IgG1 Monoclonal Antibody against Polyribosyl Ribitol Phosphate (IgG1) on Ingestion of H. influenzae type b (Eagan Isolate) by Resident Mouse Peritoneal Macrophages

\begin{tabular}{|c|c|c|c|c|c|c|}
\hline \multirow[b]{2}{*}{ Opsonin } & \multirow[b]{2}{*}{ C3 fixation ${ }^{*}$} & \multirow[b]{2}{*}{ ELISA titer } & \multicolumn{4}{|c|}{ Number of organisms/macrophage* } \\
\hline & & & Inoculum size mean $\pm \mathrm{SE}$ & Total associated & Bound & Ingestion index $x^{8}$ \\
\hline & & & CFU/Mac & & & \\
\hline $8 \%$ NI-S $(n=8)$ & yes & $<1: 10^{\#}$ & $409 \pm 90$ & $9.3 \pm 2.9$ & $8.1 \pm 1.8$ & $0.11 \pm 0.10$ \\
\hline $8 \%$ Con-S $(n=5)$ & yes & $1: 2,560$ & $433 \pm 111$ & $7.6 \pm 2.0$ & $3.5 \pm 1.4^{* *}$ & $0.55 \pm 0.11$ \\
\hline $\operatorname{IgG1}(n=8)$ & no & $1: 320$ & $408 \pm 60$ & $6.7 \pm 3.4^{\pi}$ & $0.9 \pm 0.8^{* *}$ & $0.87 \pm 0.10$ \\
\hline
\end{tabular}

* Mean number of organisms/macrophage $\pm \mathrm{SD}$ as determined by immunofluorescent microscopy following methanol fixation (total associated) and formalin fixation (bound). ${ }^{\ddagger} \mathrm{C} 3$ deposition on $H$. influenzae type $\mathrm{b}$ as determined by immunofluorescent assay using FITC-conjugated goat anti-mouse C3. Experiments performed with $\mathrm{IgG} 1$ were done in the absence of fresh serum. ${ }^{\S}$ Ingestion index \pm standard deviation. Index was calculated for each experiment as: 1 - (organisms bound/total organisms associated). Ingestion indices for experiments performed in $8 \%$ Con-S and IgG1 were significantly different as determined by rank sum, $P<0.05$, compared to NI-S. "Antibody titer of IgG and IgM determined by ELISA using whole organisms. 'Difference not significant, $P>0.1$, when compared to organisms bound and ingested in NI-S.

** Difference significant, $P<0.01$, when compared to organisms bound in NI-S.

the early complement components and depend upon the fixation of $\mathrm{C} 3$ to the bacterial surface. This deposition of $\mathrm{C} 3$ can occur in nonimmune serum via activation of the alternative complement pathway $(6,29,30)$ and is independent of bacteriolysis. This correlation of in vivo clearance with in vitro enhancement of binding suggests that the role of complement in enhancing clearance of $H$. influenzae type b from blood is due to its ability to enhance the interaction of these bacteria with macrophages.

Previous in vitro work using PMNs suggested that complement was not sufficient to mediate phagocytosis of $H$. influenzae type b (11). In the study presented here, however, we demonstrated that incubation with nonimmune serum significantly increased the number of organisms associated with macrophage monolayers above that seen in the absence of serum (Table I). Binding was readily demonstrable in nonimmune serum that had no detectable antibody to $H$. influenzae type $b$ as determined by a whole organism ELISA. Binding also occurred despite the presence of an antibody to the Fc receptor in sufficient quantity to block IgG-coated SRBC binding. This indicated that these pathogens do interact with macrophages via serum-dependent, but antibody-independent mechanisms. Complement's role in determining this interaction was initially suggested by the reduction of binding to background levels in the presence of heat-inactivated serum or in serum from cobra venom factor-treated animals.

The specific role of C3 in mediating association of organisms with macrophages in serum was demonstrated by inhibition of this interaction with $F\left(a b^{\prime}\right) 2$ anti-mouse $C 3$ fragments. These fragments decreased the binding seen in the presence of nonimmune and of convalescent serum to levels seen in the absence of serum. This inhibition was specific, as these fragments did not inhibit IgG-coated sheep red blood cell binding or IgG1-mediated phagocytosis of $H$. influenzae (Table II). This association was further characterized as occurring largely via the macrophage complement receptor type 3 (CR3). Reagents that recognize mouse leukocyte surface proteins that bind $\mathrm{C} 3 \mathrm{~b}$-coated particles had no effect on the binding of organisms to monolayers. However, CR3 blockade using monoclonal antibody to this receptor (M1/70) inhibited over $75 \%$ of the interaction of all four isolates examined, when assayed in the presence of nonimmune serum (Fig. 4). This inhibition was specific to the alpha chain of the mouse CR3, as the interaction was not affected by monoclonal antibody directed against the beta chain of CR3. Further, NADG, used in concentrations sufficient to inhibit the binding of zymosan to macrophages, did not inhibit the binding of $H$. influenzae. These observations support the hypothesis that the complement-dependent binding seen in this in vitro system occurs largely via the macrophage CR3, and furthermore that it occurs via the alpha chain of CR3 and is independent of the lectin-like site on this receptor.

To determine whether the interaction of bacteria and macrophages reflected ingestion of the organisms, or merely their binding to the macrophage surface, we carried out immunofluorescent microscopy on monolayers fixed with either methanol or formalin. In nonimmune serum the majority of organisms (89\%) associated with monolayers were bound and not ingested. These findings are consistent with previous observations that in resident macrophages, complement receptors are more efficient in mediating binding than ingestion of $\mathrm{C} 3$ coated particles $(24,31,32)$.

Using these same immunofluorescent staining methods, binding and ingestion of organisms was assessed in the presence of antibody. Convalescent, high antibody titer serum increased the percentage of organisms ingested from $11 \%$ to $55 \%$. The number of organisms ingested in the presence of this serum was comparable to that seen when the assays were performed in the presence of a purified IgG1 monoclonal against type $b$ capsule (E117-5). The increased ingestion in the presence of convalescent serum or with IgG1 monoclonal E117-5 alone, suggests that while $\mathrm{C} 3$ mediates the early recognition leading to bacterial binding, antibody is more effective in mediating internalization of these encapsulated bacteria. This is also suggested by the reduction in ingestion mediated by convalescent serum after incubation with monoclonal antibody to the $\mathrm{Fc}$ receptor and the sequential incubation experiments in which $\sim 50 \%$ of organisms originally bound with nonimmune serum were then ingested after subsequent incubation with either monoclonal antibody E1 17-5 or heat-inactivated convalescent serum. This effect was shown using reduced concentrations of purified monoclonal antibody that were incapable of promoting phagocytosis of organisms in the absence of fresh serum. This result is similar to that previously described with 
sheep red blood cells (33) and suggests that under certain conditions complement directed binding can synergize with antibody-mediated macrophage ingestion of $H$. influenzae type $b$. This function may be critical in determining the ingestion of organisms by macrophages in the presence of low concentrations of opsonic antibody.

Our earlier in vivo studies (6) demonstrated that $\mathrm{C} 3$ opsonization is associated with the early blood clearance of $H$. influenzae type $b$. The results of the in vitro studies presented here suggest that complement directs this early clearance of organisms from blood by enhancing the interaction of organisms with macrophages. This interaction occurs in the absence of antibody and would be expected to increase reticuloendothelial sequestration of organisms similar to that previously described with other encapsulated bacteria in the nonimmune host (34). The reversibility or permanence of this sequestration, and the effect of this process on bacterial viability remain open questions. The importance of complement mediated binding to macrophages, however, should not only be considered as an antibody-independent mechanism of defense but also one that may be critical for determining antibody-mediated clearance in the immune host as well. This is suggested by our observation that complement was required for ingestion of bacteria in the presence of either convalescent serum or concentrations of monoclonal antibody that were incapable of promoting phagocytosis on their own.

This study demonstrates the importance of complement in mediating phagocytosis of $H$. influenzae type b by the macrophage and indicates that a better understanding of the immunology of $H$. influenzae type $\mathrm{b}$ infection awaits further definition of the interaction of these organisms with macrophages.

\section{Acknowledgments}

We thank the Department of Otorhinolaryngology at The New York Hospital and the late Dr. Robert W. Selfe for their support of this work and Elias Coutavas, Larry Miller, and Diane Bauer for their technical assistance.

This research was supported by BRS grant S07 RR05396-26 awarded by the Biomedical Research Support Grant Program, Division of Research Resources, National Institutes of Health. NIH grant AI-19888, and Dr. Mosser is supported in part by U. S. PHS grant AI24313.

\section{References}

1. McCarty, M. 1973. Host parasite relations in bacterial infections. In Microbiology. B. D. Davis, editor. Harper and Row, Hagerstown, MD. 627-665.

2. Musher, D., A. Goree, T. Murphy, A. Chapman, J. Zahradnik, M. Apicella, and R. Baughn. 1986. Immunity to Haemophilus influenzae type $\mathrm{b}$ in young adults: correlation of bactericidal and opsonizing activity of serum with antibody to polyribosylribitol phosphate and lipooligosaccharide before and after vaccination. J. Infect. Dis. 154:935-943.

3. Cates, K. L., K. H. Marsh, and D. M. Granoff. 1985. Serum opsonic activity after immunization of adults with Haemophilus influenzae type b-diptheria toxoid conjugate vaccine. Infect. Immun. 48:183-189.

4. Cates, K. L. 1985. Serum opsonic activity for Haemophilus influenzae type $\mathrm{b}$ in infants immunized with polysaccharide-protein conjugate vaccines. J. Infect. Dis. 152:1076-1077.

5. Newman, S. L., and L. K. Mikus. 1985. Deposition of C3b and C3bi onto particulate activators of the human complement system. $J$. Exp. Med. 161:1414-1431.
6. Noel, G. J., S. Katz, and P. J. Edelson. 1988. Complement-mediated early clearance of Haemophilus influenzae type b from blood is independent of serum lytic activity. J. Infect. Dis. 157:85-90.

7. Rogers, D. E. 1960 . Host mechanisms which act to remove bacteria from the blood stream. Bacteriological Rev. 24:50-66.

8. Moxon, E. R., A. L. Smith, D. R. Averill, and D. H. Smith. 1974. Haemophilus influenzae meningitis in infant rats after intranasal inoculation. J. Infect. Dis. 129:154-162.

9. Sutton, A., R. Schneerson, S. Kendall-Morris and J. B. Robbins. 1982. Differential complement resistance mediates virulence of Haemophilus influenzae type b. Infect. Immun. 35:95-104.

10. Musher, D. M., D. A. Watson, M. L. Lepow, P. McVerry, R. Hamill and R. E. Baughn. 1988. Vaccination of 18-month-old children with conjugated polyribosyl ribitol phosphate stimulates production of functional antibody to Haemophilus influenzae type b. Pediatr. Infect. Dis. 7:156-159.

11. Schreiber, J. R., V. Barrus, K. L. Cates, and G. R. Siber. 1986. Functional characterization of human IgG, IgM and IgA antibody directed to the capsule of Haemophilus influenzae type b. J. Infect. Dis. 153:8-16.

12. Rubin, L. G., A. Zwahlen, and E. R. Moxon. 1985. Role of intravascular replication in the pathogenesis of experimental bacteremia due to Haemophilus influenzae type b. J. Infect. Dis. 152:307313.

13. Crosson, F. J., J. A. Winklestein and E. R. Moxon. 1976. Participation of complement in the nonimmune host defense against experimental Haemophilus influenzae type b septicemia and meningitis. Infect. Immun. 14:882-887.

14. Ross, S. C., and P. Densen. 1984. Complement deficiency states and infection: epidemiology, pathogenesis and consequences of neisserial and other infections in an immune deficiency. Medicine (Baltimore). 63:243-273.

15. Winklestein, J. A., and E. R. Moxon. 1982. Role of complement in the host's defense against Haemophilus influenzae. In Haemophilus influenzae, Epidemiology, Immunology and Prevention of Disease. S. H. Sell and P. F. Wright, editors. Elsevier, New York. 135-143.

16. Gordon, D. L., G. M. Johnson, and M. K. Hostetter. 1986. Ligand-receptor interactions in the phagocytosis of virulent Streptococcus pneumoniae by polymorphonuclear leukocytes. J. Infect. Dis. 154:619-626.

17. Horwitz, M. A., and S. C. Silverstein. 1980. Influence of the Escherichia coli capsule on complement fixation and on phagocytosis and killing by human phagocytes. J. Clin. Invest. 65:82-94.

18. Payne, N. R., and M. A. Horowitz. 1987. Phagocytosis of Legionella pneumophilia is mediated by human monocyte complement receptors. J. Exp. Med. 166:1377-1389.

19. Zwahlen, A., L. G. Rubin, C. J. Connelly, T. J. Inzana, and E. R. Moxon. 1985. Alteration of the cell wall of Haemophilus influenzae type $\mathrm{b}$ by transformation with cloned DNA: association with attenuated virulence. J. Infect. Dis. 152:485-492.

20. Pelton, S. I., P. A. Shurin, J. O. Klein, and M. Finland. 1977. Quantitative inhibition of Haemophilus influenzae by trimethoprim/ sulfamethoxazole. Antimicrob. Agents Chemother. 12:649-654.

21. Mosser, D. M., and P. J. Edelson. 1985. The mouse macrophage receptor for C3bi (CR3) is a major mechanisms in the phagocytosis of leishmania promastigotes. J. Immunol. 135:2785-2789.

22. Storrie, B., and P. J. Edelson. 1977. Distribution of concanavalin A in fibroblasts: direct endocytosis versus surface capping. Cell. 11:707-717.

23. Ross, G. D., J. A. Cain, and P. J. Lachman. 1985. Membrane complement receptor type three (CR-3) has lectin-like properties analogous to bovine conglutinin and functions as a receptor for zymosan and rabbit erythrocytes as well as a receptor for iC3b. J. Immunol. 134:3307-3315.

24. Unkeless, J. C., and S. D. Wright. 1988. Phagocytic cells: Fc and complement receptors. In Inflammation: Basic Principles and 
Clinical Correlates. J. I. Gallin, I. M. Goldstein, and R. Snyderman editors. Raven Press, Inc., New York. 343-362.

25. Unkeless, J. C. 1979. Characterization of a monoclonal antibody directed against mouse macrophage and lymphocyte Fc receptors. J. Exp. Med. 150:580-596.

26. Paul, M. S., M. Aegerter, S. F. O'Brien, C. B. Kurtz, and J. H. Weis. 1989. The murine complement receptor gene family: analysis of mCRY gene products and their homology to human CR1. J. Immunol. 142:582-589.

27. Kinoshita, T., J. Takeda, K. Hong, H. Sakai, and K. Inque. 1988. Monoclonal antibodies to mouse complement receptor type 1 (CR1). J. Immunol. 140:3006-3072.

28. Swinscow, T. D. V. 1976. Statistics at Square One. British Medical Association, London. 86pp.

29. Tarr, P. I., S. W. Hosea, E. J. Brown, R. Schneerson, A. Sutton, and M. M. Frank. 1982. The requirement of specific anticapsular IgG for killing of Haemophilus influenzae by the alternative pathway of complement activation. J. Immunol. 128:1772-1775.

30. Quinn, P. H., F. J. Crosson, J. A. Winklestein, and E. R. Moxon. 1977. Activation of the alternative complement pathway by Haemophilus influenzae type b. Infect. Immun. 16:400-402.

31. Griffin, F. M., Jr., C. Bianco, and S. C. Silverstein. 1975. Characterization of the macrophage receptor for complement and demonstration of its functional independence from the receptor for the Fc portion of imminoglobulin G. J. Exp. Med. 141:1269-1277.

32. Wright, S. D. 1985. Cellular strategies in receptor-mediated phagocytosis. Rev. Infect. Dis. 3:395-397.

33. Ehlenberger, A. G., and V. Nussenzweig. 1977. The role of membrane receptors for $\mathrm{C} 3 \mathrm{~b}$ and $\mathrm{C} 3 \mathrm{~d}$ in phagocytosis. J. Exp. Med. 145:357-371.

34. Hosea, S. W., E. J. Brown, and M. M. Frank. 1980. The critical role of complement in experimental pneumococcal sepsis. $J$. Infect. Dis. 142:903-909. 